\title{
Temas actuales en bioética
}

\section{Fernando Lolas Stepke}

Este número de Acta Bioethica se compone de trabajos de muy diversa procedencia y aborda temas de amplia variedad. En su trilingualismo atestigua también el impacto y la recepción que la revista ha alcanzado en diversos contextos culturales y lingüísticos.

Desde tópicos abstractos hasta análisis empíricos, los artículos de esta edición interpelan a lectores muy diversos. Críticamente, podría argumentarse que no todos constituyen un discurso que pudiera rotularse de "bioético". Sin embargo, al mismo tiempo esta pluralidad de temas, enfoques, perspectivas y audiencias recuerda que el núcleo disciplinario del discurso bioético es múltiple. Esta porosidad es una debilidad evidente, toda vez que casi todo podría entonces pasar por legítima producción bioética, pero en otros sentidos puede decirse que esfuerzos de integración como esta revista representan una vía para formar identidad. Si es que esta fuera una necesaria o deseable meta.

Durante muchos años, nos hemos preguntado en el Centro Interdisciplinario de Estudios en Bioética de la Universidad de Chile cuánto de beneficio habría en "profesionalizar" la bioética. Inconscientemente, hacia ello tendieron los esfuerzos que, mientras existió el Programa de Bioética de la Organización Panamericana de la Salud, hicimos en conjunto para instalar maestrías en distintas universidades latinoamericanas. Personas que completaron tales estudios se preguntaron luego por las perspectivas laborales que ellos facilitarían. Como la respuesta no siempre fue inequívoca, podría explicar las dificultades que algunos de tales programas enfrentaron para reclutar estudiantes.

Tener "bioeticistas" profesionales podría ser positivo, siempre que sus ámbitos de trabajo estuvieran delineados y delimitados. Por otra parte, como reiteradamente comprobamos, raras son las instituciones que reconocen el trabajo de comités y comisiones como auténtico trabajo digno de ser remunerado como otras actividades. Es frecuente que la evaluación ética de la práctica asistencial o el análisis de proyectos de investigación se consideren actividades adicionales al trabajo clínico o académico habitual y no sean reconocidas como dignas de figurar en el presupuesto institucional.

Sin duda, lo bioético queda por ahora mejor definido como modulación de la actividad profesional, como una exhortación a tener en cuenta las consecuencias morales de las decisiones, como una cualificación del quehacer especializado, indispensable en sus efectos, pero no necesariamente excluyente de otras actividades. De hecho, enfocar bioéticamente las ciencias y los oficios brinda un nuevo paradigma para su enseñanza y su ejercicio. Pues de lo que se trata es que las acciones valgan no solamente por sus fines sino también por los medios de que se sirven quienes las ejecutan. Si algo ha traído el enfoque bioético en ciencia es una preocupación por el "cómo" tanto como por el "qué". Y esto, obviamente, supone preocuparse por "quién”, esto es, por la formación espiritual de los científicos y los técnicos.

La constitución disciplinaria es de suyo un proceso histórico. Depende del reclutamiento de cultores acreditados en instituciones solventes y de productos apreciados por pares ilustrados. Es probable que no pueda acelerarse ni retardarse. Es menester esperar la consolidación a través de los productos escritos, que cuantitativamente son coextensivos con el discurso disciplinario y cualitativamente suelen adquirir retórica propia y modos de producción aceptados y establecidos. Será interesante observar este desarrollo en el área por ahora laxamente denominada bioética. Pues a su oscuridad y polisemia contribuye no poco el uso político y económico de sus contenidos y la confusa mezcolanza entre derechos humanos, prácticas sociales, justicia, filosofía y cuidado de la salud que, al menos en algunas partes del mundo, han terminado por desprestigiar el discurso. 
Los temas de este número de la revista pueden, por ello, ser considerados actuales. Esto es, han sido objeto de atención por parte de autores que los juzgaron relevantes y se motivaron a escribir sobre ellos. Confiamos que la revista, foro abierto, pluralista y cuidadoso de las heterogeneidades, algo contribuirá a decantar aquello que, más allá de la actualidad, se convertirá en núcleo persistente de la bioética. 